http://jmscr.igmpublication.org/home/ ISSN (e)-2347-176x ISSN (p) 2455-0450

crossref DOI: https://dx.doi.org/10.18535/jmscr/v7i9.30

\title{
Antidermatophytic Effect of $M$ Lucida Part Extracts (Ethanolic and Aqueous) on Selected Clinical Isolates
}

\author{
Authors \\ Owolabi, S.L ${ }^{1}$, Azeez I.A ${ }^{2}$, Boyejo A.O ${ }^{3}$, Issah A.O \\ ${ }^{1}$ Department of Science Laboratory Technology (Biology unit), Gateway Polytechnic (ICT) Saapade, \\ Ogun -State, Nigeria \\ ${ }^{2}$ Department of biological sciences Tai Solarin University of Education, Ijagun, Ijebu ode, Ogun State, \\ Nigeria \\ ${ }^{3,4}$ Department of Medical Microbiology Olabisi Onabanjo University, Ago-Iwoye, Ogun state, Nigeria
}

\begin{abstract}
Dermatophytoses are the most frequent fungal infections worldwide, affecting individuals in various age groups and heading to worse quality of life and economic burden due to treatment expenditure. Hence this study was carried out to determine the effect of Morida lucida parts extract on dermatohytes.

Twenty-five gram (25g) of the plant sample was weighed into a $250 \mathrm{ml}$ sample bottle, $300 \mathrm{ml}$ of the different solvents were added, the solvents used were ethanol and water. The mixture was allowed to stand for 72 hours (3days) then filtered. The filtrates were concentrated using a rotary evaporator. Phytochemical screening was carried out on the extracts, Anti-dermatophytic effect of the Morinda lucida extracts was evaluated by the well plate agar diffusion method. A sterile cork borer was used to make wells (6mm in diameter) on the agar plates. Aliquots of $0.1 \mathrm{ml}$ of extract, was filled into each of the wells in the culture plates previously inoculated with the test organisms. Each well was labeled appropriately. Control experiments were also carried out where the holes were filled with $0.1 \mathrm{ml}$ of Fluconazole (200mg) as positive control. Minimum Inhibitory Concentration (MIC) and minimum fungicidal concentration (MFC) of Morinda lucida parts extracs were respectively carried out by micro tube dilution method on the isolates. Phytochemical screening analysis revealed the presence of alkaloids, flavonoids, saponins, tannins, steroids, and glycoside. The result of MIC and MFC showed higher effect of aqueous bark extract on all the isolates, followed by ehanolic bark extract.

Aqueous bark extract was observed with the highest MIC and MFC effects on all the isolates.
\end{abstract}

\section{Introduction}

Cutaneous mycoses are among the most common fungal infections and are mostly caused by filamentous keratinophilic fungi that use keratin as a nutrient during skin, hair, and nail infection. These fungi are called dermatophytes and are classified into three genera, Trichophyton, Microsporum and Epidermophyton, based on the formation and morphology of their conidia (structures of asexual reproduction). In addition, species of dermatophytes are divided into zoophilic, geophilic or anthropophilic, depending on their primary habitat (animals, soil or humans, respectively). Zoophilic species are responsible for about $30 \%$ of human dermatophytoses and they often provoke acute inflammation; 
anthropophilic species represent about $70 \%$ of infections on these hosts, causing a chronic infection of slow progression, suggesting that the fungus has adapted to the human host. So far, about 30 species of dermatophytes have been identified among human pathogens. ${ }^{1}$ The transmission of dermatophytoses or tineas occurs by direct contact with infected animals and humans or by indirect contact with contaminated fomites. The clinical forms vary according to the etiologic agent (species) and the anatomical site involved. Symptoms may be mild or severe based on the host's immunologic condition, and invasion of subcutaneous tissues or internal organs normally does not occur. Typical lesions of skin infection are circular, erythematous and pruritic, and are the result of direct action of the fungus or hypersensitivity reactions to the microorganism and/or its metabolic products. In nail infections (onychomycosis) the nail may separate from its bed, may become thick and have white spots or even become distrophic. ${ }^{2}$ Although infections by dermatophytes are usually restricted to the superficial epidermis, these fungi may be invasive and cause a severe and disseminated infection in immunocompromised patients, with the development of dermatophytic granulomas. ${ }^{3}$ According to the World Health Organization (WHO), dermatophytes affect about $25 \%$ of the world population. It has been estimated that from 30 to $70 \%$ of adults are asymptomatic hosts of these pathogens and that the incidence of the disease increases with age. Generally, dermatophytes exhibit a cosmopolitan profile, that is, they are found in different regions of the world with variations in the frequency of particular species, as geoclimatic and social conditions interfere with the distribution of dermatophyte species. ${ }^{4}$ Climatic factors, social practices, migration and individual characteristics may influence the epidemiology of dermatophytoses. Moreover, some risk factors have been associated with onychomycoses, such as age, abnormalities in nail morphology, genetic factors, poor hygiene conditions, diabetes melittus, immunodeficiency. ${ }^{4}$ Reports suggest that hormonal rates affect the frequency of these infections in men and women and that steroid hormones may influence the growth of these pathogens. Some species of Trichophyton and Microsporum have cytosolic proteins that bind exclusively and with high affinity to progesterone; the latter, in pharmacological and physiological concentration, inhibits the growth of dermatophytes in a dose-dependent manner. Anthropophilic species respond better to the action of steroids than geophilic species. ${ }^{5}$

An epidemiological evaluation involving 16 countries in Europe showed that between 35 and $40 \%$ of the analyzed individuals had infection of the foot (tinea pedis) caused by dermatophytes. ${ }^{6}$ In addition, a study conducted with children in daycares in the United States revealed that between 22 to $50 \%$ of them exhibited symptoms of dermatophyte infection of the hair scalp. ${ }^{7}$ In Brazil, the Southern and Southeast regions have a high incidence of infections caused by the dermatophyte Trichophyton rubrum, followed by Microsporum

canis and Trichophyton mentagrophytes, whereas in the Northeast, Trichophyton tonsurans, T. rubrum and $M$. canis predominate. ${ }^{8,}{ }^{9}$ In the State of Sao Paulo, 4,500 children (0-15 years old) were evaluated to determine the incidence of tinea capitis from 1996 to 2000 . Of the 132 children with suspicion of infection, $112(85 \%)$ received confirmation through direct microscopy and culture. The most common isolates were $M$. canis $(70.5 \%)$ and $T$. tonsurans (23.2\%), followed by $T$. mentagrophytes (3.6\%), Microsporum gypseum (1.8\%) and T. rubrum $(0.9 \%){ }^{10}$

Among the fungi isolated from skin infections, the anthopophilic dermatophyte T. rubrum is the most frequent in clinical cases of tinea pedis (feet), tinea unguium (nails), tinea corporis (body) and tinea cruris (groin region). ${ }^{4}$ Epidemiological studies conducted with university students from Sao Paulo demonstrated the occurrence of dermatophytes in $18.2 \%$ of the studied population; T. rubrum was isolated in $80 \%$ of the 
cases and T. mentagrophytes, in $20 \% .{ }^{11}$ Among onychomycoses, T.rubrum is also the most prevalent dermatophyte, affecting children and adults in about $33.2 \%$ of the cases identified in Sao Paulo, followed by $T$. mentagrophytes $(6.3 \%) .{ }^{12}$ In Fortaleza, a three-year study described the isolation of dermatophytes in $12.99 \%$ of the cases of onychomycosis; $T$. rubrum was isolated in $9.04 \%$ of the patients and T. tonsurans and T. mentagrophytes, in $2.54 \%$ and $1.41 \%$, respectively. ${ }^{13}$

Morinda lucida Benth., belonging to the family Rubiaceae is a tropical rainforest tree with the English name "Brimstone tree". It is also known as Sangogo or Bondoukou alongua (in Cote d'Ivoire), Twi, Kon kroma or Ewe amake (in Ghana), Ewe amake or Atak ake (in Togo) and Oruwo or Ruwo amongst the Yoruba tribe (Southwest Nigeria) and Huka or Eze-ogu amongst the Igbo speaking tribe of South-east Nigeria (Adeneye, 2013). It is a medium size tree about $15 \mathrm{~m}$ tall with scaly grey bark, short crooked branches and shining foliage. In West Africa, Morinda lucida is an important plant in traditional medicine. In Nigeria, Morinda lucida is one of the four most used plants in the preparation of traditional medicines against fever (Lawal, Etatuvie, and Fawehinmi, 2011). The leaves are used as "oral teas", which are usually taken orally for the traditional treatment of malaria, and as a general febrifuge, analgesic, laxative and antiinfections. The major constituents of M. lucida extract are the various types of alkaloids, anthraquinones and anthraquinols. Two compounds (oruwalol and oruwal) and anthraquinones have been isolated and characterized from the stem of the plant. In SouthWest Nigeria, fresh leaves of the plant are macerated in fresh palm wine and the filtrate taken orally for blood sugar control in suspected diabetic patients. The leaves have also been reported to possess strong hypoglycemia, trypanocidal and aortic vasorelaxant activities (Adeneye, 2013). Further studies have shown that leaf and stem bark of $M$. lucida posses anticancer
(Sowemimo, Fakoya, Awopetu, Omobuwajo, and Adesanya, 2007), hepatoprotective (Oduola, T., Bello. I., Adeosun, Ademosun, Raheem, Avwioro, 2010), antispermatogenic (Raji, Akinsomisoye, and Salman, 2005), and antidiabetic activity. The stem bark, roots and leaves infusion of M. lucida is used as an antimalarial, antidiabetic, jaundice and dysentery treatment and it is used in antimalarial activity, anti-Salmonella typhi activity, effect on contractility of isolated uterine smooth muscle of pregnant and nonpregnant mice, toxicity and mutagenic studies and it has antidiabetic property. $M$. lucida extracts have been reported to have antioxidant and reducing activities, and antimicrobial activity. The major constituents of $M$. lucida extracts were found to be: essential oils, anthraquinones and anthraquinols. Oruwalol, oruwal, ursolic acid, and oleanolic acid were also isolated from this plant. The red colorants of M. lucida were confirmed to be 1-methyl-ether-alizarin, rubiadin and derivatives, lucidin, soranjidiol, damnacanthal, nordamnacanthal, morindin, munjistin and purpuroxanthin, anthraquinones, oruwacin, tannins, flavonoids, digitolutein, and saponosides were isolated from different parts of M. lucida. The root of M. lucida is used as chewing sticks are for oral hygiene in Nigeria. The aqueous extracts of different parts of this plant were found to be effective against Staphylococcus aurens, Bacillus subtilis, Escherichia coli, and Pseudomonas aeruginosa.

\section{Material and Method}

\section{Collection and Authentication of Sample}

Twenty five gram (25 g) of fresh stem bark of Morinda lucida were collected from Gateway (ICT) Polytechnic Saapade botanical garden. The harvested plant materials were processed for voucher referencing as previously described by Adeneye and Agbaje (2008). The fresh stem bark peels were gently rinsed under tap water and dried under room temperature protected from direct heat and sunlight for 4 weeks. Afterwards, the dried samples were pulverized using laboratory 
hammer-mill in the hing Hospital, Department of Pharmacognosy, Faculty of Pharmacy, Olabisi Onabanjo University Teac, Ogun State, Nigeria.

\section{Extraction}

Twenty-five gram $(25 \mathrm{~g})$ of the plant sample was weighed into a $250 \mathrm{ml}$ sample bottle, $300 \mathrm{ml}$ of the different solvents were added, and the solvents used were ethanol and water. The mixture was allowed to stand for 72 hours (3days) then filtered. The filtrates were concentrated using a rotary evaporator.

\section{Phytochemical Screening}

This was done on the different extracts to ascertain the presence of bioactive components present in leave. The presence of alkaloids, resins, Saponin, glycoside, tannins, Flavonoids, cardiac glycoside steroidal ring, steroidal terpens, Anthraquinone and carbohydrates were determined as described by (Okwu 2005, Sofowora 1993; Trease and Evans 2002)

\section{Test for Tannins}

About $5 \mathrm{ml}$ portion of the of the sample was stirred and shaken with $10 \mathrm{ml}$ of distilled water and then filtered, few drops of $1 \%$ ferric chloride solution were added to $2 \mathrm{ml}$ of the filtrate, occurrence of a blue - black, or blue - green precipitate indicated the presence tannins (Trease and Evans, 2002).

\section{Test for Anthraquinone}

About $2 \mathrm{ml}$ of some portion to be tested was shaken with $10 \mathrm{ml}$ of benzene and then filtered. $5 \mathrm{ml}$ of the $10 \%$ ammonia solution was then added to the filtrate and thereafter was shaken appearance of a pink, red or violet colour in the ammonical (lower) phase showed as the presence of free anthraguinons (Sofowora, 1993)

\section{Test for Saponin}

Two (2) $\mathrm{ml}$ of the sample was boiled with $20 \mathrm{ml}$ distilled water in the water bath. The mixture filtered, way about $5 \mathrm{ml}$ of distilled water was added to $10 \mathrm{ml}$ of the filtrate, this was shaken vigorously for a stable persistent froth. The frothing was mixed with 3 drops of olive oil, shaken vigorously and then observed for the formation of emulsion (Okwu, 2005).

\section{Test for Flavonoids}

$5 \mathrm{ml}$ of $10 \%$ dilute ammonia solution was added to a portion of the plant extracts followed by addition of concentrated $\mathrm{H}_{2} \mathrm{SO}_{4}$. A yellow coloration observed in the extracts indicated the presence of Flavonoids (Okwu, 2005).

\section{Test for Alkaloids}

Few quantities of the samples was stirred with $5 \mathrm{ml}$ of $1 \%$ aqueous HCL on water bath and then filtered, $1 \mathrm{ml}$ was placed into 2 test tubes, to the first portion, a few drops of Dragendorff's reagent were added; occurrence of orange - red precipitate was taken as positive. To the second 1ml, Mayer's reagent was added and appearance of buff - color, showed the presence of alkaloids (Sofowora, 1993).

\section{Test for Cardiac Glycosides}

Five milliliters $(5 \mathrm{ml})$ of the extracts were treated with $2 \mathrm{ml}$ of glacial acetic acid containing 1 drop of ferric chloride solution $(0.1 \%)$. This was underplayed with $1 \mathrm{ml}$ of concentrated $\mathrm{H}_{2} \mathrm{SO}_{4}$, a brown ring of the interface indicated a deoxysugar characteristic of cardenolides. A violet ring may appear below the ring. While in the acetic layer a greenish ring may form just gradually throughout their layer (Okwu, 2005).

\section{Test for Steroids}

Two milliliters $(2 \mathrm{ml})$ of acetic anhydride was added to $0.5 \mathrm{ml}$ of each extract this was followed by the additional off with $2 \mathrm{ml} \mathrm{H}_{2} \mathrm{SO}_{4}$. The colour changed from violet to blue or green in some sample indicating the presence of steroids (Okwu, 2005).

\section{Determination of antifungal activity (Agar well diffusion method)}

Anti-dermatophytic effect of the Morinda lucida extracts was evaluated by the well plate agar 


\section{JMSCR Vol||07||Issue||09||Page 188-194||September}

diffusion method. The dermatophyte cultures were adjusted to equal 0.5 McFarland turbidity standards and inoculated on PDA ( Oxoid) plate (diameter $9 \mathrm{~cm}$ ). The plates were flooded with $1 \mathrm{ml}$ of each of the standardized test organism, swirled and excess inoculum was carefully decanted. A sterile cork borer was used to make wells $(6 \mathrm{~mm}$ in diameter) on the agar plates. Aliquots of $0.1 \mathrm{ml}$ of extract, was filled into each of the wells in the culture plates previously inoculated with the test organisms. Each well was labeled appropriately. Control experiments were also carried out where the holes were filled with $0.1 \mathrm{ml}$ of Fluconazole (200mg) as positive control. However, the experiment was done in duplicates. The plates were then left on the bench for 30 minutes for proper diffusion of the extracts. Thereafter, the plates were incubated at $37{ }^{\circ} \mathrm{C}$ for 24 hours.

Minimum Inhibitory Concentration (MIC)

Minimum Inhibitory Concentration (MIC) of Morinda lucida was performed on the isolates by microtube dilution method. The 96 well microtiter plate was used for this bio-assay and each well was labelled.

\section{Minimum Fungicidal Concentration (MFC) assay}

Sub-culturing was made from each well showing no growth including the MIC well onto SDA plate. Following incubation at 37c for seven days, the plate was examined for growth of dermatophytes.

\section{Results}

Table 1: Phytochemical Characteristics of Root Bark and Leaf extracts of Morinda lucida

\begin{tabular}{|l|c|c|c|c|c|c|}
\hline \multirow{2}{*}{ Parameters } & \multicolumn{3}{|c}{ Root } & \multicolumn{2}{c|}{ Bark } & \multicolumn{2}{c|}{ Leaf } \\
\cline { 2 - 7 } & Ethanol & Aqueous & Ethanol & Aqueous & Ethanol & Aqueous \\
\hline Alkaloids & $0.37 \pm 0.3$ & $0.29 \pm 0.2$ & $0.39 \pm 0.2$ & $0.35 \pm 0.1$ & $0.45 \pm 0.5$ & $0.41 \pm 0.2$ \\
\hline Flavonoids & $0.26 \pm 0.2$ & $0.21 \pm 0.1$ & $0.28 \pm 0.1$ & $0.21 \pm 0.2$ & $0.35 \pm 0.2$ & $0.35 \pm 0.3$ \\
\hline Saponins & $0.25 \pm 0.1$ & $0.21 \pm 0.0$ & $0.27 \pm 0.3$ & $0.25 \pm 0.3$ & $0.30 \pm 0.2$ & $0.28 \pm 0.2$ \\
\hline Tannins & $0.31 \pm 0.1$ & $0.28 \pm 0.2$ & $0.32 \pm 0.3$ & $0.30 \pm 0.2$ & $0.37 \pm 0.1$ & $0.30 \pm 0.1$ \\
\hline Steroids & $0.24 \pm 0.2$ & $0.18 \pm 0.1$ & $0.26 \pm 0.0$ & $0.24 \pm 0.1$ & $0.29 \pm 0.2$ & $0.25 \pm 0.2$ \\
\hline Glycoside & $0.19 \pm 0.1$ & $0.15 \pm 0.2$ & $0.21 \pm 0.2$ & $0.19 \pm 0.1$ & $0.25 \pm 0.3$ & $0.21 \pm 0.1$ \\
\hline Anthraquinone & $0.12 \pm 0.1$ & $0.10 \pm 0.0$ & $0.14 \pm 0.0$ & $0.10 \pm 0.0$ & $0.18 \pm 0.2$ & $0.14 \pm 0.1$ \\
\hline
\end{tabular}

Table 2 Anti-dermatophytic effect of Morinda lucida part extracts

\begin{tabular}{|c|c|c|c|c|c|c|c|}
\hline \multirow[t]{3}{*}{ Dermatophytes } & \multicolumn{6}{|c|}{ M. lucida/ Mean $( \pm$ SD)Zone diameter $(\mathrm{mm})$} & \multirow[t]{3}{*}{ Control } \\
\hline & \multicolumn{2}{|c|}{ Root } & \multicolumn{2}{|c|}{ Bark } & \multicolumn{2}{|c|}{ Leaf } & \\
\hline & Ethanol & Aqueous & Ethanol & Aqueous & Ethanol & Aqueous & \\
\hline M. audouinii & $18.0 \pm 0.2$ & $15.0 \pm 1.0$ & $19.0 \pm 1.0$ & $14.0 \pm 2.0$ & $22.0 \pm 2.0$ & $19.0 \pm 1.0$ & $25.0 \pm 1.0$ \\
\hline M. ferrugineum & $15.0 \pm 0.0$ & $11.0 \pm 0.0$ & $17.0 \pm 1.0$ & $10.0 \pm 1.0$ & $18.0 \pm 1.0$ & $15.0 \pm 2.0$ & $27.0 \pm 0.0$ \\
\hline E.floccosum & $19.0 \pm 0.5$ & $17.0 \pm 1.0$ & $19.0 \pm 0.5$ & $14.0 \pm 2.0$ & $23.0 \pm 1.0$ & $21.0 \pm 0.5$ & $25.0 \pm 0.0$ \\
\hline T.schenieni & $12.0 \pm 1.0$ & $10.0 \pm 0.0$ & $15.0 \pm 1.0$ & $11.0 \pm 1.0$ & $17.0 \pm 1.0$ & $14.0 \pm 1.0$ & $26.0 \pm 0.0$ \\
\hline T.rubrum & $10.0 \pm 0.0$ & $7.0 \pm 1.0$ & $13.0 \pm 1.0$ & $10.0 \pm 0.5$ & $18.0 \pm 0.5$ & $15.0 \pm 0.5$ & $25.0 \pm 0.5$ \\
\hline T.metagrophyte & $12.0 \pm 0.5$ & $9.0 \pm 1.0$ & $15.0 \pm 0.5$ & $13.0 \pm 1.0$ & $21.0 \pm 1.0$ & $19.0 \pm 1.0$ & $25.0 \pm 0.0$ \\
\hline
\end{tabular}

Controls - Fluconazole

Table 3 Minimum Inhibitory Concentration (MIC) of Morinda lucida part extracts.

\begin{tabular}{|l|c|c|c|c|c|c|c|}
\hline \multirow{2}{*}{ Dermatophytes } & \multicolumn{3}{|c|}{ M. lucida/ MIC (\% v/v) } & \multicolumn{3}{c|}{ Control } \\
\cline { 2 - 8 } & \multicolumn{2}{|c|}{ Root } & \multicolumn{2}{c|}{ Bark } & \multicolumn{2}{c|}{ Leaf } \\
\cline { 2 - 8 } & Ethanol & Aqueous & Ethanol & Aqueous & Ethanol & Aqueous & \\
\hline M. audini & 12.5 & 12.5 & 12.5 & 25.0 & 6.25 & 12.5 & 3.13 \\
\hline M. fereginum & 12.5 & 25.0 & 12.5 & 50.0 & 12.5 & 25.0 & 1.57 \\
\hline E.flocossum & 6.25 & 12.5 & 12.5 & 50.0 & 6.25 & 6.25 & 3.13 \\
\hline T.schenieni & 25.0 & 50.0 & 25.0 & 25.0 & 12.5 & 25.0 & 3.13 \\
\hline T.rubrum & 50.0 & 100.0 & 25.0 & 50.0 & 12.5 & 25.0 & 3.13 \\
\hline T.metagrophyte & 25.0 & 100.0 & 25.0 & 50.0 & 6.25 & 12.5 & 3.13 \\
\hline
\end{tabular}


Table 4 Minimum fungicidal Concentration (MFC) of Morinda lucida part extracts.

\begin{tabular}{|c|c|c|c|c|c|c|c|}
\hline \multirow[t]{3}{*}{ Dermatophytes } & \multicolumn{6}{|c|}{ M. lucida/ MBC (\% v/v) } & \multirow[t]{3}{*}{ Control } \\
\hline & \multicolumn{2}{|c|}{ Root } & \multicolumn{2}{|c|}{ Bark } & \multicolumn{2}{|c|}{ Leaf } & \\
\hline & Ethanol & Aqueous & Ethanol & Aqueous & Ethanol & Aqueous & \\
\hline M. audini & 25.0 & 25.0 & 25.0 & 50.0 & 12.5 & 50.0 & 6.25 \\
\hline M. fereginum & 25.0 & 50.0 & 25.0 & 100.0 & 25.0 & 50.0 & 3.13 \\
\hline E.flocossum & 12.5 & 50.0 & 25.0 & 100.0 & 25.0 & 12.5 & 6.25 \\
\hline T.schenieni & 50.0 & 100.0 & 50.0 & 50.0 & 50.0 & 50.0 & 3.13 \\
\hline T.rubrum & 100.0 & 100.0 & 50.0 & 100.0 & 50.0 & 50.0 & 6.25 \\
\hline T.metagrophyte & 50.0 & 100.0 & 50.0 & 100.0 & 25.0 & 25.0 & 6.25 \\
\hline
\end{tabular}

Controls - Fluconazole

\section{Discussion}

Table 1 shows the result of phytochemical screening of Morinda lucida part exracts, the following bioactive constituent were observed Saponin, alkaloid, flavonoid, tannins, steroid, and glucoside. This result corroborates the findings of (Adeneye, 2013).The root, bark, and leaf ehanolic and aqueous extracts were observed with essential bioactive constituents.

Table 2 Shows. anti-dermatophytic effect of Morinda lucida part extracts, all dermatophytes used in this study were sensitive to ehanolic and aqueous extract, but Epidemophyton flocussom was highly sensitive to aqueous and ethanolic extracts.

Table 3. Minimum Inhibitory Concentration (MIC) of Morinda lucida part extracts reveals susceptibility of the isolates to different concentrations of the $M$ lucida part exracts with the following results 12.5on $M$ audounii, (ethanolic and aqueous extracst,), $M$ audounii, Tmentagrophyte, and $T$ rubrum respectively. Highest susceptibity was observed in $M$ fereginum( 50.aqueous exract).

Table 4. Minimum fungicidal Concentration (MFC) of Morinda lucida part extracts.shows high susceptibility of all the isolatess to bark, root and leaf extracts(ethanolic and aqueos).

\section{Conclusion}

This work has demonstrated that Morinda lucida part extracts possesses broad spectrum antifungal activity against dermatophytes, because all the isolates used in this study were susceptible to aqueous and ethanolic extracts of Morinda lucida parts extract

\section{Reference}

1. Achterman, R.R. and White, T.C. (2012). Dermatophyte Virulence Factors: Identifying and Analyzing Genes that may contribute to Chronic or Acute Skin Infections. International Journal of Microbiology. 18.

2. Adejumobi, J.A., Ogundiya, M.O., Kolapo, A.L., Okunade, M.B. (2008). Phytochemical composition and in vitro antimicrobial activity of Anogeissus leiocarpus on some common oral pathogens. Journal for Medicinal Plants.2: 193-196.

3. Ajello, L. (1968). A taxonomic review of the dermatophytes and related species. Sabouraudia 6: 147-159.

4. Ameen, M. (2010). Epidermiology of superficial fungal infections. Clinical Dermatology.28: 197-201.

5. Azoro, C. (2002). Antibacterial activity of crude extract of Azadiractaindica of Salmonella typhi. World Journal for Biotechnology. 3: 347-357

6. Dawson, C.O. and Gentles, J.C. (1961). The perfect states of Keratinomyces ajelloi Vanbreuseghem, Trichophytonterrestre Durie and Frey and Microsporumnanum Fuentes. Sabouraudia 1: 49-57.

7. Graser, Y., Scott, J., Summerbell, R. (2008). The new species concept in dermatophytes- a polyphasic approach. Mycopathologia.166: 239-256.

8. Gupta, A.K. and Cooper, E.A. (2008). "Update in antifungal therapy of 
dermatophytosis, Mycopathologia. 166: 353-367.

9. Havlickova, B., Czaika, V.A. and Markus Friedrich, M. (2008). Epidemiological trends in skin mycoses worldwide. Blackwell Publishing Limited for Mycoses.51:2-15.

10. Kamalam, A., Thambiah A.S.(1979). Tineacapitis in a Moslem school. Indian Journal for Medical Respiration.70: 40-3.

11. Murray, P.R., Baron, E.J., Jorgensen, J.H., Landry, M.L., Pfaller, M.A. (2007). Manual of Clinical Microbiology. 9th edition. 2.

12. Nwinyi, O.C., Chinedu, N.S., Ajani, O.O. (2008). Evaluation of antibacterial activity of Pisidium guajava and Gongronema latifolium Journal for Medicinal plants.2: 189-192

13. Ogwumike, O.O. (2002). Hemopoietic effect of aqueous extract of the leaf sheath of Sorghum bicolour in abino rats. African Journal for Biomedical Respiration.5: 6971. 